\title{
Evaluation of Yield and Yield Contributing Characters of Heat Tolerant Potato (Solanum tuberosum L.) Genotypes in Bangladesh
}

\author{
M. H. Rahman ${ }^{1}$, M. M. Alam Patwary ${ }^{1}$, H. Barua ${ }^{1}$, M. Hossain ${ }^{2}$ and S. Nahar ${ }^{3}$ \\ ${ }^{1}$ Agricultural Research Station, Bangladesh Agricultural Research Institute, Pahartali, Chittagong \\ ${ }^{2}$ Bangladesh Agricultural Research Institute, Gazipur, ${ }^{3}$ Agriculture Extension Officer, Metropolitan \\ Agriculture office, Pachlaish, Chittagong, Bangladesh
}

*Corresponding author and Email: kbdmhrahman@gmail.com

Received: 11 April 2013

Accepted: 14 June 2014

\begin{abstract}
Eight heat tolerant CIP (International Potato Centre) potato genotypes along with BARI (Bangladesh Agricultural Research Institute) Alu-7 (Diamant) and one local variety (Dohazari Sada) were evaluated at Agricultural Research Station, Pahartali, Chittagong during 2011-12 to identify heat tolerant genotypes from varieties and CIP clones of potato. Diamant and Dohazari Sada and all the heat tolerant CIP genotypes were found to grow well up to $60 \mathrm{DAP}$ (days after planting) against heat having healthy plants and no senescence was noticed. After that $61-100 \%$ plants died due to high temperature $\left(29.8^{\circ} \mathrm{C}\right)$ depending on the genotypes. Genotype CIP 139 gave the highest yield $(14.18 \mathrm{t} / \mathrm{ha})$ and was comparatively less affected by heat than the other genotypes. The high dry matter $(22.43 \%)$ accumulated in the local variety Dohazari Sada.
\end{abstract}

Keywords: Potato, heat tolerant, yield, germplasm

\section{Introduction}

Potato (Solanum tuberosum L.) originated in the Andes of South America (Hawkes, 1992) where it was cultivated mostly at an altitude between 2000 and $4000 \mathrm{~m}$ in a region characterized by short day length, high light intensity, low temperature and high humidity. From there, the potato was introduced to Europe, where potato is grown under long days, moderate temperatures and modern cultivation methods. In these regions, potato is grown in the summer, and water deficiency may be a yield limiting factor (Harris, 1978; Burton, 1981).

High temperatures which prevail during most of the time of a year pose major limitation in potato production in many countries (Dodds, 1990).
Reductions in leaf area, tuber number and weight have been reported as symptoms of elevated temperatures during the growth of potato plants (Menzel, 1985). Low temperatures, especially low night temperatures, increase the number of tubers per plant. At higher temperatures when fewer tubers per plant are formed, larger tubers are obtained. Although increases in either day or night temperatures above optimal levels reduce tuber yields, high night temperatures seem to be more deleterious (Gregory, 1956).

Both high air and soil temperatures cause yield reduction (Gregory, 1965). Jones et al. (1922) found that soil temperature influenced tuber yield, with the optimum at 15 to $18{ }^{\circ} \mathrm{C}$. Higher soil temperatures decreased tuber yields, especially when combined with high ambient air 
temperatures $\left(30{ }^{0} \mathrm{C}\right.$ day $/ 23{ }^{0} \mathrm{C}$ night $)$. At low light intensity, in the winter season, maximum tuber weight was obtained at 12 to $14{ }^{0} \mathrm{C}$. In the summer season, when light intensity is higher, maximum tuber weight was obtained at 18 to 20 ${ }^{0} \mathrm{C}$.

At present, Bangladesh is producing about 8 to 10 million tones of potatoes per year. In the year 2009-10, potato ranked $2^{\text {nd }}$ among the best 20 commodities in terms of international price from the produce (FAOSTAT, 2010), which indicated that potato is the $2^{\text {nd }}$ most important crop in Bangladesh in terms of output. At present, Bangladesh is holding $8^{\text {th }}$ position in world ranking and $3^{\text {rd }}$ position in Asia with regards to potato production. Potato is the $3^{\text {rd }}$ most important food crop next to rice and wheat.

In Bangladesh, due to some unfavorable environmental conditions such as delayed rain and late harvesting of $\mathrm{T}$. Aman rice, potato plantation is delayed and at the later part of Rabi season temperature becomes higher. So, the objective of the present investigation was to identify the potato genotypes suitable for cultivation under high temperature to mitigate the effect of climate change in Bangladesh.

\section{Materials and Methods}

Eight heat tolerant CIP genotypes viz., CIP 6, CIP 7, CIP 115, CIP 127, CIP 129, CIP 139, LB 12 and LB 14 along with BARI Alu-7 (Diamant) and one local variety (Dohazari Sada) having heat tolerance potentials were evaluated at the Agricultural Research Station, Pahartali, Chittagong during January to March, 2012. The experiment was laid out in a randomized complete block design with three replications. The unit plot size was $3.0 \mathrm{~m} \times 1.8 \mathrm{~m}$. Fertilizers were applied @ 250-150-250-120 kg/ha of urea, TSP, MoP and Gypsum, respectively (Mandal et al., 2011). Full amount of TSP, MoP and Gypsum and $50 \%$ of urea were applied as basal and the remaining amount of urea was side dressed at 35 DAP (days after planting).

Tubers were planted on 02 January, 2012 with a spacing of $60 \mathrm{~cm} \mathrm{X} 25 \mathrm{~cm}$. Weeding, irrigation, earthing up and other intercultural operations were done as per recommendation developed by Tuber Crops Research Centre, BARI, Gazipur, Bangladesh. Botanical characters of the potato genotypes under investigation were recorded (Table 1). Data on temperature, sunshine hour, rainfall and relative humidity during the study period were recorded and presented in Fig. 1.

Table 1. Botanical characteristics of heat tolerant potato genotypes

\begin{tabular}{|c|c|}
\hline Genotypes & Characters \\
\hline CIP 6 & $\begin{array}{l}\text { White Skin and yellow flesh colour, round shape, fleet type eyes, medium to } \\
\text { large size tuber }\end{array}$ \\
\hline CIP 7 & White Skin and yellow flesh colour, medium to large, round to oblong size tuber \\
\hline CIP 115 & White skin and creamy white flesh, oblong, pinkish slight deep eyes tuber \\
\hline CIP 127 & White skin and creamy white flesh, round to oblong, medium to large size tuber \\
\hline CIP 129 & $\begin{array}{l}\text { White skin and yellow flesh colour, round to flat, shallow eyes, Medium to large } \\
\text { size tuber }\end{array}$ \\
\hline CIP 139 & $\begin{array}{l}\text { Red skin and yellowish white flesh, medium to large size, fleet type eyes, round } \\
\text { shape tuber }\end{array}$ \\
\hline LB 12 & Red skin and yellowish white flesh, round, medium to large size tuber \\
\hline LB 14 & White skin and yellow flesh, round to oblong, medium size tuber \\
\hline $\begin{array}{l}\text { BARI Alu-7 } \\
\text { (Diamant) }\end{array}$ & $\begin{array}{l}\text { White skin and creamy white flesh, Oblong, fleet eyes small to medium size } \\
\text { tuber }\end{array}$ \\
\hline Dohazari Sada & $\begin{array}{l}\text { White skin and yellowish white flesh, pinkish and slight deep eyes, small size } \\
\text { tuber }\end{array}$ \\
\hline
\end{tabular}




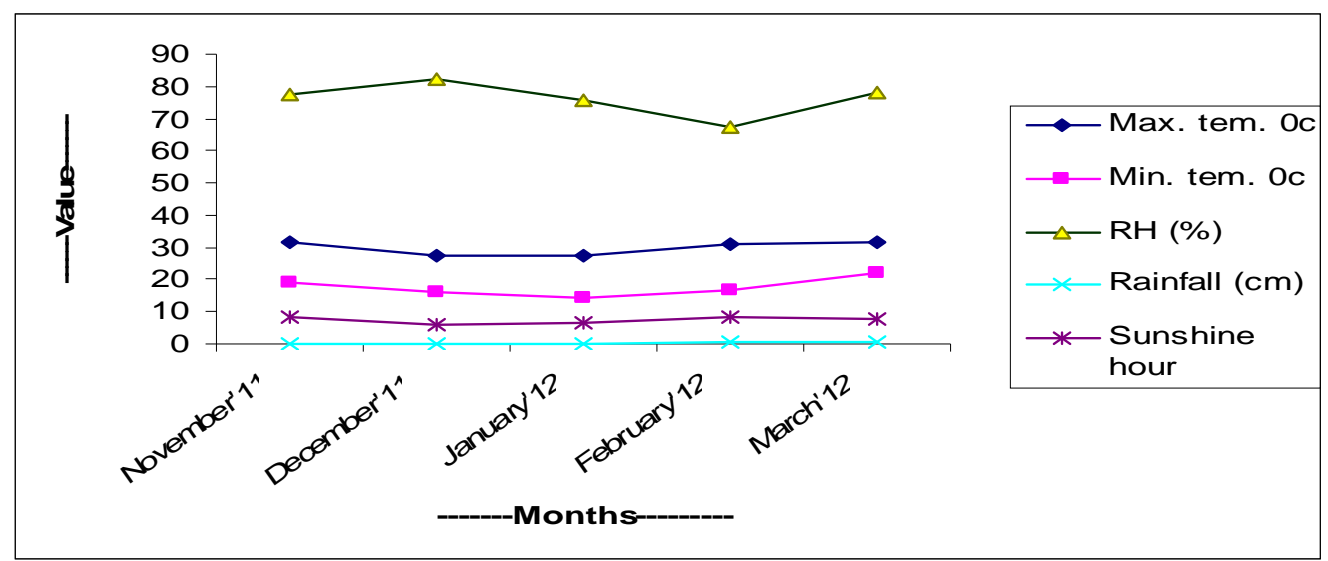

Fig. 1. Average weather data at different times of the crop season

All data on yield and yield contributing characters were recorded. Data on sprouting percent, plant vigor, number of compound leaves, plant height $(\mathrm{cm})$, number of stem per plant, foliage coverage percent, senescence, tuber number and weight per plot, tuber number and weight per plant, yield (t/ha) and dry matter were collected. Plant vigor data were also recorded on $1-5$ scale where: vigor $1=$ very poor, $2=$ poor, $3=$ good, $4=$ very good and $5=$ excellent plant vigor and for senescence; $1=0-20 \% ; 2=$ $21-40 \%, 3=41-60 \%, 4=61-80 \%$ and $5=81-$ $100 \%$ dry plant foliage (Anon, 2011-12). Tubers were also graded as marketable $(>20 \mathrm{~g})$ and non marketable $(<20 \mathrm{~g})$ by weight basis. In case of local variety (Dohazari Sada) very small tuber $(<5 \mathrm{~g})$ was considered as non marketable tuber. Data were analyzed statistically and the means were separated by Least Significant Difference (LSD) following MSTATC software.

\section{Results and Discussion}

Tubers were harvested on 30 March, 2012. All the information and data of the experiment are presented in Tables 1, 2 and 3 and Fig. 1. The yield and yield contributing characters of the genotypes varied significantly. All the genotypes showed more than 95\% emergence except LB 12 and LB 14. Considering plant vigour, CIP 7 and CIP 139 were excellent, while LB 12 and LB 14 and Diamant showed poor vigour.
All the CIP genotypes had good number of compound leaves per plants ranging from 30.93 to 54.86 at $45 \mathrm{DAP}$ and 34.60 to 57.80 at 60 DAP. The local variety Dohazari Sada had the highest number of compound leaves per plant (70.13 at 45 DAP and 77.07 at 60DAP) (Table 2)

Plant height at 45 and 60 DAP varied significantly among all genotypes ranging from 33.33 to 52.80 and 38.60 to $64.67 \mathrm{~cm}$, respectively. These results compare closely with other works (http://en.wikipedia.org/wiki/Potato), where the reported potato plants were herbaceous perennials that grow about $60 \mathrm{~cm}$ ( 24 inches) heights, depending on variety.

Number of stems per plant was significantly different among the studied genotypes. The highest number (7.40) of stem was found in Dohazari Sada. Percent ground foliage coverage showed significant variations among the genotypes (Table 2).

The highest number (29.0) of tubers per plant was recorded in the local variety Dohazari Sada. The lowest number (3.70) of tubers per plant was recorded from CIP 7. Tuber weight per plant varied significantly among the genotypes and the highest weight $(215.0 \mathrm{~g})$ was obtained from LB 14 , while the lowest was recorded from LB 12 (61.42g) (Table 3). 
Table 2. Yield contributing characters of heat tolerant potato genotypes

\begin{tabular}{|c|c|c|c|c|c|c|c|c|c|c|}
\hline \multirow[t]{2}{*}{ Genotypes } & \multirow{2}{*}{$\begin{array}{l}\text { Germination } \\
\% \text { at } 45 \text { DAP }\end{array}$} & \multicolumn{2}{|c|}{ Plant vigor at } & \multicolumn{2}{|c|}{$\begin{array}{l}\text { No. of compound } \\
\text { leaves at }\end{array}$} & \multicolumn{2}{|c|}{ Plant height $(\mathrm{cm})$ at } & \multirow{2}{*}{$\begin{array}{l}\text { Stem no. } \\
\text { /plant at } \\
60 \text { DAP }\end{array}$} & \multicolumn{2}{|c|}{ Foliage coverage $(\%)$ at } \\
\hline & & 45 DAP & 60 DAP & 45 DAP & 60 DAP & 45 DAP & 60 DAP & & 45 DAP & 60 DAP \\
\hline CIP 6 & 97.22 & 4.67 & 4.33 & 54.86 & 56.80 & 52.80 & 60.33 & 5.26 & 78.33 & 83.33 \\
\hline CIP 7 & 100.00 & 5.00 & 4.67 & 46.93 & 48.87 & 47.47 & 56.07 & 4.67 & 75.00 & 81.67 \\
\hline CIP 115 & 95.36 & 4.67 & 4.67 & 49.00 & 57.80 & 50.53 & 64.67 & 4.73 & 76.67 & 85.00 \\
\hline CIP 127 & 100.00 & 4.67 & 5.00 & 33.00 & 35.73 & 38.80 & 45.20 & 2.46 & 70.00 & 78.33 \\
\hline CIP 129 & 98.14 & 4.67 & 4.33 & 31.20 & 34.60 & 43.07 & 51.20 & 3.07 & 71.67 & 76.67 \\
\hline CIP 139 & 99.07 & 5.00 & 5.00 & 43.26 & 49.67 & 36.67 & 42.47 & 4.60 & 80.00 & 88.33 \\
\hline LB 12 & 48.14 & 3.33 & 2.33 & 30.93 & 36.60 & 38.53 & 50.33 & 2.47 & 45.00 & 51.67 \\
\hline LB 14 & 40.73 & 4.00 & 3.00 & 44.73 & 46.87 & 40.93 & 49.87 & 4.27 & 46.67 & 53.33 \\
\hline Diamant & 100.00 & 5.00 & 1.33 & 44.13 & 46.80 & 37.53 & 41.33 & 4.33 & 65.00 & 58.33 \\
\hline Dohazari Sada & 99.07 & 4.33 & 3.67 & 70.13 & 77.07 & 33.33 & 38.60 & 7.40 & 68.33 & 70.00 \\
\hline $\mathrm{CV}(\%)$ & 5.67 & 12.66 & 17.82 & 17.90 & 17.02 & 6.13 & 7.10 & 23.92 & 8.33 & 10.44 \\
\hline $\mathrm{LSD}_{0.05}$ & 8.54 & 0.98 & 1.17 & 13.76 & 14.33 & 4.41 & 6.09 & 1.77 & 9.66 & 13.02 \\
\hline Level of significance & $* *$ & $*$ & $* *$ & $* *$ & $* *$ & $* *$ & $* *$ & $* *$ & $* *$ & $* *$ \\
\hline
\end{tabular}

$*$ and $* *$ significant at $5 \%$ and $1 \%$, respectively. DAP= Days after planting 
Table 3. Yield and yield contributing characters of heat tolerant potato genotypes

\begin{tabular}{|c|c|c|c|c|c|c|c|c|c|}
\hline \multirow{2}{*}{ Genotypes } & \multicolumn{3}{|c|}{ Senescence at } & \multirow{2}{*}{$\begin{array}{l}\text { Tuber no. } \\
\text { /plant }\end{array}$} & \multirow{2}{*}{$\begin{array}{c}\text { Tuber } \\
\text { wt.(g)/plant }\end{array}$} & \multicolumn{3}{|c|}{ Yield (t/ha) } & \multirow{2}{*}{ DM \% } \\
\hline & 60 DAP & 67 DAP & 70 DAP & & & Marketable & $\begin{array}{c}\text { Non } \\
\text { Marketable }\end{array}$ & Total & \\
\hline CIP 6 & 1.67 & 3.33 & 5 & 5.04 & 194.28 & 12.47 & 0.12 & 12.59 & 20.21 \\
\hline CIP 7 & 2.33 & 3.67 & 5 & 3.70 & 140.46 & 9.23 & 0.13 & 9.36 & 18.29 \\
\hline CIP 115 & 2.00 & 3.67 & 5 & 5.22 & 111.30 & 6.82 & 0.26 & 7.07 & 16.88 \\
\hline CIP 127 & 2.00 & 3.00 & 5 & 4.60 & 176.39 & 11.60 & 0.16 & 11.75 & 19.83 \\
\hline CIP 139 & 1.00 & 2.33 & 4 & 5.17 & 214.63 & 14.09 & 0.08 & 14.18 & 21.32 \\
\hline LB 12 & 1.67 & 3.33 & 5 & 3.82 & 61.42 & 2.05 & 0.13 & 2.18 & 21.37 \\
\hline LB 14 & 2.33 & 4.00 & 5 & 6.64 & 215.00 & 5.14 & 0.17 & 5.31 & 19.71 \\
\hline Diamant & 4.00 & 5.00 & 5 & 6.22 & 160.27 & 10.59 & 0.09 & 10.68 & 18.37 \\
\hline Dohazari Sada & 2.67 & 4.67 & 5 & 29.00 & 99.24 & 4.85 & 1.71 & 6.56 & 22.43 \\
\hline $\mathrm{LSD}_{0.05}$ & 0.72 & 0.97 & 0.31 & 1.93 & 67.10 & 1.85 & 0.41 & 1.87 & 0.09 \\
\hline Level of significance & $* *$ & $* *$ & $* *$ & $* *$ & $* *$ & $* *$ & $* *$ & $* *$ & $* *$ \\
\hline
\end{tabular}

$*$ and $* *$ significant at $5 \%$ and $1 \%$, respectively. DAP= Days after planting 
Among all the genotypes, CIP 139 was the best yielder (14.18 t/ha), while LB 12 gave the lowest yield (2.18 t/ha). CIP 6 (12.59 t/ha) and CIP 127 $(11.75 \mathrm{t} / \mathrm{ha})$ were also found to be promising and they produced comparatively better yield than the popular variety Diamant (10.68 t/ha) (Table $3)$. These results were comparable to those reported elsewhere (http://en.wikipedia.org/wiki/Potato), where the average world farm yield for potato was 17.4 $\mathrm{t} / \mathrm{ha}$, in 2010 . The yield of potato varied with climatic variations viz., temperature, rainfall, relative humidity and sunshine hour etc. (Fig. 1). The high dry matter $(22.43 \%)$ was accumulated from the local variety Dohazari Sada.

\section{Conclusions}

From the result, it is evident that in Bangladesh, higher temperature decreases the yield of potato. However, among the genotypes studied, CIP 139 with yield of 14.18 t/ha was found to be promising against temperature up to $29.8^{\circ} \mathrm{C}$. Further investigation is needed with these genotypes for releasing as heat tolerant variety.

\section{References}

Annual Report, 2011-12. Tuber Crops Research Centre, BARI, Gazipur, Bangladesh, 36, $47 \mathrm{pp}$.

Burton W. G. 1981. Challenges for stress physiology in potato. American Journal of Potato, 58: 3-14.

Dodds, J. H. 1990. Molecular Biology of Potato: Current and future Prospects for Developing Countries. In: The Molecular and Cellular Biology of the Potato
Biotech Agriculture (Eds): M. E. Vaydr and W. Park. 13: 223-232.

FAO. 2010.2 FAOSTAT. http://faostat.fao.org/Potato.

Gregory, L. E. 1956. Some factors of tuberization in plants. American Journal of Botany, 43: 281-288.

Gregory, L. E. 1965. Physiology of tuberization in plants. Plant Physiology, 15: 13281354.

Harris, P. M. 1978. Water. In: P. M. Harris (ed), The Potato Crop: The Scientific Basis for Improvement. Chapman \& Hall, London. 245-277 pp.

Hawkes, J. G. 1992. History of the potato. In: P. M. Harris (ed), The Potato Crop: The Scientific Basis for Improvement, Ed 2. Chapman and Hall, London. 1-12 pp.

Jones, L. R., H. H. McKinney and H. Fellows. 1922. The Influence of Soil Temperature on Potato Scab. Wisconsin Agricultural Experiment Station Bulletin. No. 53.

Menzel, C. M. 1985. Tuberization in Potato at High Temperatures: Interaction between Temperature and Irradiance. Annals of Botany, 55: 35-39.

Mandal, M. R. I., M.S. Islam, M. A. J. Bhuyan, M. M. Rahman and M. H. H. Rahman (Eds.). 2011. Krishi Projukti Hatboi ( in bengali). $2^{\text {nd }}$ part. $5^{\text {th }}$ edn. Bangladesh Agricultural Research Institute. Gazipur, 1701. Bangladesh. 282-307 pp.

http://en.wikipedia.org/wiki/Potato. 15 January 2013. 